\title{
Murcha Bacteriana no Estado do Amazonas, Brasil
}

\author{
Rosalee A. Coelho Netto ${ }^{1}$, Bianca G. Pereira ${ }^{1}$, Hiroshi Noda ${ }^{1} \&$ Bernard Boher $^{2}$ \\ 'Instituto Nacional de Pesquisa da Amazônia, Coordenação de Pesquisa em Ciências Agronômicas, \\ Cx. Postal 478, CEP 69011-670, Manaus, AM; ${ }^{2}$ UR 075, Résistance des Plantes, Centre IRD, B.P. 5045, \\ 34032 Montpellier, France, e-mail: rcoelho@ inpa.gov.br
}

(Aceito para publicação em 14/11/2003)

Autor para correspondência: Rosalee A. Coelho Netto

COELhO NETTO, R.A., PEREIRA, B.G., NODA, H. \& BOHER, B. Murcha bacteriana no estado do Amazonas, Brasil. Fitopatologia Brasileira 29:021-027. 2004.

\section{RESUMO}

Durante 1998 e 2000, a incidência de murcha bacteriana causada por Ralstonia solanacearum foi registrada em 25 municípios do estado do Amazonas. A bactéria foi encontrada nas seguintes espécies vegetais: Capsicum annuum, $C$. chinense, $C$. frutescens, Cucumis sativus, Heliconia sp., Lycopersicon esculentum, Melanthera discoidea, Moringa oleifera, Musa sp., Solanum melongena, S. gilo, e $S$. nigrum. Em tomateiros (Lycopersicon esculentum), a murcha bacteriana estava presente em todos os plantios. Em bananeiras (Musa spp.), a incidência do Moko foi menor nas várzeas dos rios Madeira e Negro do que nas dos rios Solimões e Amazonas. Caracterizaram-se
320 isolados de $R$. solanacearum, obtidos no levantamento, com relação a raça e a biovar. A biovar 1 predominou em todos os hospedeiros, com exceção de $C$. annuum e $C$. chinense, onde estirpes da biovar 3 foram maioria. Apenas 7,8\% das estirpes foram da biovar N2. A sensibilidade de 56 estirpes da raça 1 a 23 bacteriocinas foi avaliada. As estirpes da biovar 3 apresentaram uma menor variabilidade, na sensibilidade a bacteriocinas do que as estirpes das biovares 1 e N2.

Palavras-chave aadicionais: Ralstonia solanacearum, Pseudomonas solanacearum, Burkholderia solanacearum, bacteriocinas.

\section{ABSTRACT}

\section{Bacterial wilt in Amazonas State, Brazil}

A survey for bacterial wilt caused by Ralstonia solanacearum was conducted in 25 counties in the state of Amazonas during the years 1998 and 2000. Ralstonia solanacearum was found in the following species: Capsicum annuum, $C$. chinense, $C$. frutescens, Cucumis sativus, Heliconia sp., Lycopersicon esculentum, Melanthera discoidea, Moringa oleifera, Musa sp., Solanum melongena, S. gilo, and $S$. nigrum. In tomatoes (Lycopersicon esculentum), bacterial wilt was present in all fields. In banana (Musa spp.), the incidence of
Moko disease was lower in the flooded areas of the Madeira and Negro Rivers than in the Solimões and Amazonas Rivers. In this survey the race and biovar of $320 R$. solanacearum isolates was determined. The biovar 1 strains predominate in almost all hosts. In C. annuum and $C$. chinense, however, biovar 3 was more common. Only $7.8 \%$ of the strains were biovar N2. Fifty-six race 1 strains originating from different hosts and counties were evaluated with regard to sensitivity to 23 bacteriocins. Strains from biovars 1 and N2 showed more variability regarding bacteriocin sensitivity than biovar 3 strains.

\section{INTRODUÇÃO}

No estado do Amazonas, a atividade humana concentrase nas várzeas dos rios, onde os agricultores aproveitam a maior fertilidade dos solos, submetidos a períodos de alagamento, para as atividades agrícolas. As várzeas baixas, onde o solo permanece imerso por até oito meses, são utilizadas principalmente para o cultivo de espécies olerícolas. Dentre essas se encontram diversos hospedeiros conhecidos de Ralstonia solanacearum (Smith) Yabuuchi et al., como o tomateiro (Lycopersicon esculentum Mill.), o pimentão (Capsicum annuum L.), a pimenta-de-cheiro (Capsicum chinense Jacq.), a pimenta malagueta (Capsicum frutescens L.), a berinjela (Solanum melongena L.) e o pepino (Cucumis sativus L.). Nas várzeas altas, raramente alagadas, cultiva-se, em muitos municípios, a bananeira (Musa spp.), outra hospedeira da bactéria. Nas áreas livres das enchentes, chamadas de terra firme, os solos são geralmente de textura arenosa, com baixa fertilidade e, primariamente, cobertos por floresta. Solos de terra firme são também utilizados, após o desmatamento, para o cultivo de bananeira. Algumas áreas de terra firme, em torno das cidades maiores, são utilizadas para o cultivo de hortaliças, em ambiente protegido e com adubação orgânica.

A murcha bacteriana é favorecida por condições de umidade e temperatura altas e chega a inviabilizar o cultivo de diversas espécies em regiões com clima temperado quente, tropical ou subtropical (Hayward, 1991). Fenotipicamente, a espécie é dividida em cinco raças, com base na reação de uma gama de hospedeiras (Buddenhagen et al., 1962; He et al., 1983), e em cinco biovares, com base em propriedades bioquímicas (Hayward, 1994). Essas divisões são de importância fundamental na caracterização dos isolados da espécie. A produção de bacteriocinas também tem sido usada como uma ferramenta para tipificar e identificar espécies de bactérias. Assume-se, de uma maneira geral, que as bacteriocinas possuem um importante papel na dinâmica 


\section{R.A. Coelho Neto et al.}

populacional das bactérias no solo e que a resistência a bacteriocinas, ou a produção das mesmas, seja uma importante característica competitiva no solo (Frey et al., 1996).

No Brasil, a murcha bacteriana tem-se apresentado como um sério problema principalmente nas Regiões Nordeste e Norte (Reifschneider \& Takatsu, 1985). Na região Amazônica, a doença se constitui um sério problema para o cultivo de solanáceas e a produção local fica quase que restrita a pequenas hortas caseiras. Em bananais, a murcha-bacteriana, mais conhecida como Moko, tem se alastrado para novas áreas, quase sempre através de mudas infetadas, causando severas perdas de produção e abandono de áreas de cultivo. O conhecimento sobre a ocorrência e a variabilidade de $R$. solanacearum na bacia Amazônica, está fragmentado e baseado na inclusão de poucos isolados da Região em alguns estudos (Martins et al., 1988; Martins \& Takatsu, 1990; Melo et al., 1999). O objetivo desse trabalho foi avaliar a variabilidade de $R$. solanacearum, proveniente de diversas hospedeiras, no estado do Amazonas, visando fornecer subsídios para estudos de resistência varietal e de origem e disseminação do patógeno.

\section{MATERIALEMÉTODOS}

\section{Levantamento}

No período de 1998 a 2000 foram visitados plantios de hortaliças e bananais em 25 municípios do estado do Amazonas: Anamã, Autazes, Benjamim Constant, Boca do Acre, Carauari, Coari, Codajás, Eirunepé, Fonte Boa, Humaitá, Iranduba, Itacoatiara, Manacapuru, Manaus, Manicoré, Maués, Novo Airão, Parintins, Presidente Figueiredo, Rio Preto da Eva, São Gabriel da Cachoeira, Silves, Tabatinga, Tefé e Urucurituba (Figura 1). Nas áreas visitadas, plantas apresentando sintomas de murcha foram coletadas e levadas para exame em laboratório. $R$. solanacearum foi isolada, a partir de tecidos vasculares descoloridos do caule das plantas, utilizando-se o meio diferencial de Kelman (Kelman, 1954).

\section{Caracterização bioquímica dos isolados}

Os isolados de $R$. solanacearum foram submetidos a uma caracterização parcial através dos seguintes testes: lise da parede celular em hidróxido de potássio, atividade de oxidase, hidrólise do amido, atividade de esterase (hidrólise do Tween), redução do nitrato, crescimento em meio contendo $2 \%$ de cloreto de sódio e reação de hipersensibilidade em folha de fumo (Nicotiana tabacum L.) (Fahy \& Persley, 1983). O teste para determinação da biovar foi realizado em tubos de micro-centrífuga contendo $1,5 \mathrm{ml}$ de meio de básico com uma das diferentes fontes de carbono; glicose, lactose, maltose, celobiose, trealose, manitol, dulcitol ou sorbitol (Sigma ${ }^{\circledR}$ ) (Hayward, 1976). Após a distribuição de $50 \mu \mathrm{l}$ de suspensão bacteriana $\left(1 \times 10^{9} \mathrm{ufc} / \mathrm{ml}\right)$ em cada tubo, estes foram incubados em estufa, a $29^{\circ} \mathrm{C}$, por até 20 dias, com avaliações a cada cinco dias. A mudança da coloração do meio de verde oliva para amarela indicou a utilização, pelo isolado, da fonte de carbono contida no meio. Um controle positivo, uma estirpe de reação conhecida, e um negativo, água destilada esterilizada, foram usados nos testes. Os isolados de $R$. solanacearum, obtidos no levantamento, foram conservados em $3,5 \mathrm{ml}$ de água destilada esterilizada, em tubos de ensaio de $5 \mathrm{ml}$ a $18 / 22^{\circ} \mathrm{C}$.

\section{Determinação de raça}

Para a caracterização da raça, selecionou-se uma colônia com aspecto mucoso, de cada isolado e, após 48 h de incubação em meio de Kelman, transferiu-se a colônia para o mesmo meio, sem tetrazólio, e incubou-se por mais $24 \mathrm{~h}$, a $29^{\circ} \mathrm{C}$. A partir das colônias desenvolvidas foram preparadas suspensões, em água destilada esterilizada, contendo 1 x $10^{8} \mathrm{ufc} / \mathrm{ml}$. As suspensões foram utilizadas para inoculação de quatro mudas de bananeira cv. Prata e seis plantas das solanáceas; batata (Solanum tuberosum L.) cv. Mona Lisa, berinjela cv. Embu, pimentão cv. Yolo Wonder e tomateiro cv. Santa Cruz Kada. Vinte e oito estirpes selecionadas, provenientes de hospedeiras e localidades diversas, foram também inoculadas em plantas de pepino, cv. Verde Comprido. Para inoculação das plantas realizaram-se ferimentos no caule, com alfinete entomológico, sob uma gota de suspensão de bactérias, depositada na axila da segunda folha completamente desenvolvida, no caso das solanáceas, e na base do pseudocaule, no caso das bananeiras. Para as plantas testemunha, a suspensão de bactérias foi substituída por água destilada esterilizada. A partir do segundo dia após a inoculação, até o vigésimo, as plantas foram avaliadas quanto ao aparecimento de sintomas de murcha.

\section{Avaliação da sensibilidade a bacteriocinas}

Para a avaliação da sensibilidade de 56 estirpes a bacteriocinas produzidas por 22 estirpes de $R$. solanacearum da raça 1 e uma estirpe da raça 2 , as estirpes produtoras foram cultivadas em meio CPG (casamino-peptona-glicose) líquido (Cuppels et al., 1978) sob agitação, a $26^{\circ} \mathrm{C}$. Após três dias de incubação, as bactérias foram separadas por centrifugação (4.500 rpm, $20 \mathrm{~min}$ ) e o sobrenadante esterilizado por ultrafiltração (Millipore ${ }_{\circledast} 0,45 \mu \mathrm{l}$ ). Uma gota $(10 \mu \mathrm{l}$ ) do filtrado a ser testado foi depositada na superfície de uma camada constituída de uma mistura de $50 \mu \mathrm{l}$ da suspensão de bactérias $\left(1 \times 10^{9} \mathrm{ufc} / \mathrm{ml}\right)$ de uma das 56 estirpes alvo, com $4 \mathrm{ml}$ de meio CPG (0,8\% de ágar) fundente, distribuída em placa de Petri, contendo uma camada de ágar-água. Após 24 h de incubação a $29{ }^{\circ} \mathrm{C}$, zonas translúcidas, sem crescimento bacteriano, indicavam sensibilidade da estirpe alvo à bacteriocina. Das 51 estirpes da raça 1 testadas, 35 foram da biovar 1 e 16 da biovar 3. Cinco estirpes foram da biovar N2, raça 3 (Tabela 2). Em cada placa foram testadas até seis bacteriocinas diferentes e o experimento foi repetido duas vezes. De acordo com a reação das estirpes foi construído um dendrograma das distâncias de ligação utilizando-se o método do vizinho mais distante (complete linkage method, STATISTICA-5).

\section{RESULTADOS}

\section{Levantamento}

Sintomas de murcha em solanáceas, decorrentes da infecção por $R$. solanacearum, foram encontrados em todos 


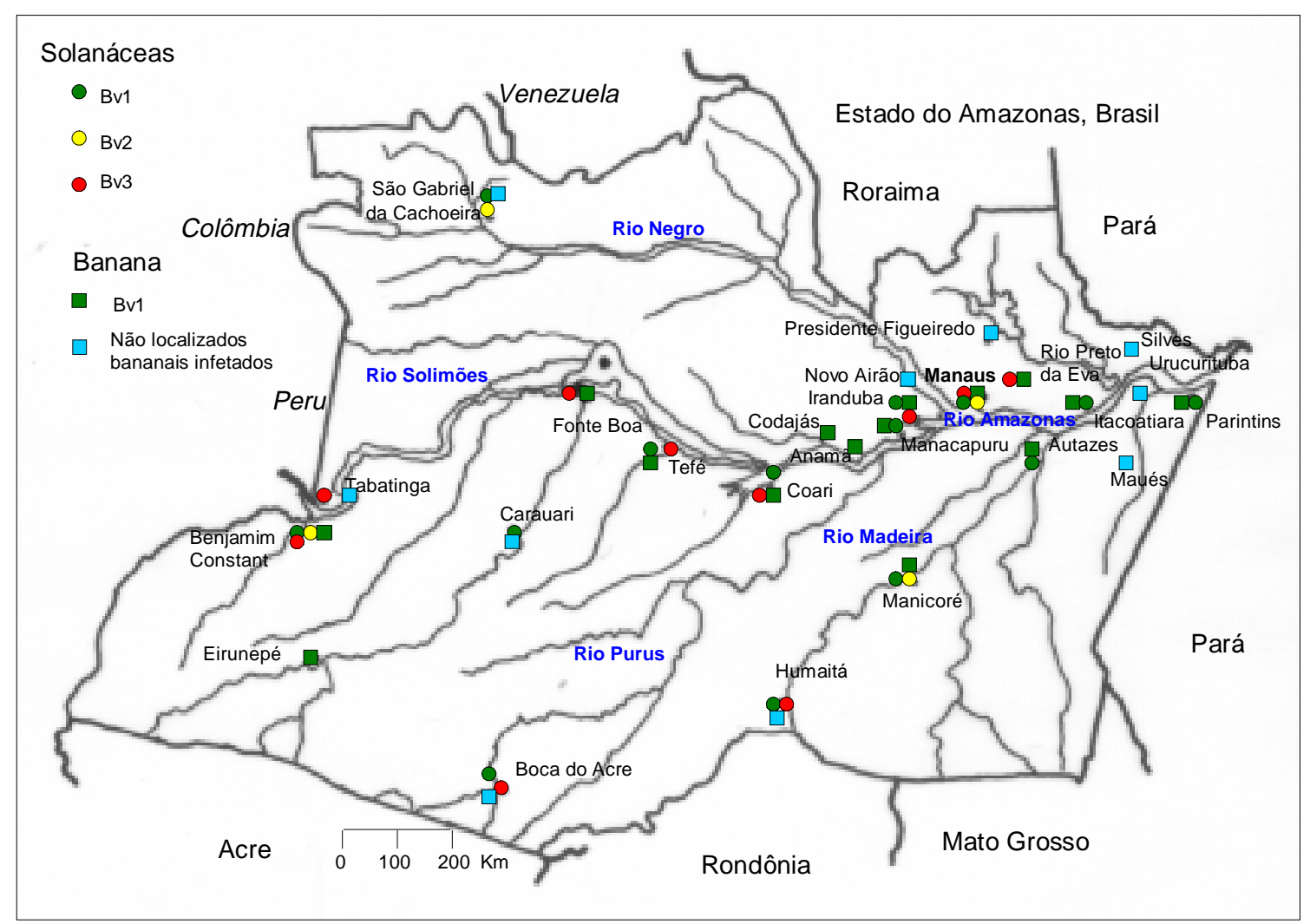

FIG. 1 - Biovares e hospedeiras de Ralstonia solanacearum identificadas em municípios do Estado do Amazonas no período de 1998 a 2000.

os municípios onde se visitaram plantios de espécies desta família. Em Anamã, Codajás, Eirunepé, Novo Airão, Maués, Silves e Urucurituba não foram visitados plantios de solanáceas. Bananeiras com sintomas de Moko foram encontradas em $70 \%$ dos municípios visitados. Nos municípios de Boca do Acre, Carauari, Humaitá, Maués, Novo Airão, Silves, São Gabriel da Cachoeira e Tabatinga, nenhum dos bananais visitados apresentavam sintomas de Moko (Figura 1). Obtiveram-se 320 isolados de $R$. solanacearum (Tabela 1). $\mathrm{O}$ cultivo de variedades suscetíveis de tomate, como as do grupo Santa Cruz, em áreas plantadas anteriormente com hospedeiras de $R$. solanacearum, acarretava, muitas vezes, a perda total do plantio. Em áreas recém desmatadas, cultivadas pela primeira vez com solanáceas observaram-se perdas de até $40 \%$ das plantas. Em cultivo protegido de pimentão, as variedades comumente utilizadas, Casca Dura e Magali, apresentaram bom nível de resistência aos isolados locais de $R$. solanacearum, e as perdas não ultrapassavam $10 \%$. A partir de pimenteiras-decheiro e malagueta, que freqüentemente apresentavam sintomas de murcha, poucas vezes conseguiu-se isolar $R$. solanacearum, podendo a murcha ser atribuída a outros agentes fitopatogênicos, não identificados. Em plantios de berinjela, pouco comuns no Estado, a incidência da murcha bacteriana chegava a causar perdas de até $40 \%$. Plantas de pepino, conhecidas como hospedeiras de $R$. solanacearum (Lopes \& Quezado-Soares, 1997), só foram encontradas com sintomas de murcha, no município de São Gabriel da Cachoeira.
TABELA 1 - Número de isolados (NI) e biovares de Ralstonia solanacearum por hospedeira, obtidos em levantamento no estado do Amazonas

\begin{tabular}{|c|c|c|c|c|c|}
\hline \multirow{2}{*}{ Hospedeira } & \multirow{2}{*}{ Família } & \multirow{2}{*}{ NI } & \multicolumn{3}{|c|}{ Biovares } \\
\hline & & & 1 & N2 & 3 \\
\hline $\begin{array}{l}\text { Tomate } \\
\text { (Lycopersicon esculentum) }\end{array}$ & Solanaceae & 107 & 60 & 24 & 23 \\
\hline $\begin{array}{l}\text { Pimentão } \\
\text { (Capsicum annuum) }\end{array}$ & Solanaceae & 41 & 18 & - & 23 \\
\hline $\begin{array}{l}\text { Pimenta-de-cheiro } \\
\text { (Capsicum chinense) }\end{array}$ & Solanaceae & 8 & 1 & - & 7 \\
\hline $\begin{array}{l}\text { Pimenta malagueta } \\
\text { (Capsicum frutescens) }\end{array}$ & Solanaceae & 2 & - & - & 2 \\
\hline $\begin{array}{l}\text { Jiló } \\
\quad \text { (Solanum gilo Raddi) }\end{array}$ & Solanaceae & 4 & 3 & 1 & - \\
\hline $\begin{array}{l}\text { Berinjela } \\
\quad \text { (Solanum melongena) }\end{array}$ & Solanaceae & 12 & 12 & - & - \\
\hline $\begin{array}{l}\text { Erva moura } \\
\quad \text { (Solanum nigrum L.) }\end{array}$ & Solanaceae & 3 & - & - & 3 \\
\hline $\begin{array}{l}\text { Banana } \\
\quad \text { (Musa sp.) }\end{array}$ & Musaceae & 86 & 86 & & - \\
\hline $\begin{array}{l}\text { Helicônia } \\
\quad \text { (Heliconia sp.) }\end{array}$ & Heliconiaceae & 4 & 4 & - & - \\
\hline $\begin{array}{l}\text { Pepino } \\
\text { (Cucumis sativus) }\end{array}$ & Cucurbitaceae & 4 & 4 & - & - \\
\hline $\begin{array}{l}\text { Moringa } \\
\quad(\text { Moringa oleifera Lam.) }\end{array}$ & Moringaceae & 8 & 8 & - & - \\
\hline $\begin{array}{l}\text { Melanthera } \\
\quad \text { (Melanthera discoidea) }\end{array}$ & Asteraceae & 17 & 15 & - & 2 \\
\hline Não identificada & Asteraceae & 3 & 3 & - & - \\
\hline Total & & 320 & 235 & 25 & 60 \\
\hline
\end{tabular}




\section{R.A. Coelho Neto et al.}

TABELA 2 - Estirpes de Ralstonia solanacearum utilizadas como produtoras de bacteriocinas e avaliadas quanto a sensibilidade a bacteriocinas

\begin{tabular}{|c|c|c|c|}
\hline Estirpe & Hospedeira & Município & Biovar \\
\hline $\mathrm{V} 1^{1}$ & Tomateiro & Benjamim Constant & 3 \\
\hline $\mathrm{V} 2^{1}$ & Tomateiro & Benjamim Constant & N2 \\
\hline V3 & Tomateiro & Benjamim Constant & 3 \\
\hline V4 & Tomateiro & Coari & 1 \\
\hline $\mathrm{V}^{1}$ & Tomateiro & Coari & 3 \\
\hline V6 & Tomateiro & Tefé & 1 \\
\hline$V 7^{1}$ & Tomateiro & Tefé & 3 \\
\hline V8 & Tomateiro & Iranduba & 1 \\
\hline $\mathrm{V}^{1}$ & Tomateiro & Iranduba & 1 \\
\hline V10 & Tomateiro & Iranduba & 1 \\
\hline V11 & Tomateiro & Autazes & 1 \\
\hline $\mathrm{V} 12^{1}$ & Tomateiro & Manaus & N2 \\
\hline V13 & Tomateiro & Manaus & N2 \\
\hline V14 & Tomateiro & Boca do Acre & 1 \\
\hline V15 & Tomateiro & Boca do Acre & 1 \\
\hline V16 & Tomateiro & Humaita & 1 \\
\hline V17 & Tomateiro & Humaita & 1 \\
\hline V18 & Tomateiro & Humaita & 3 \\
\hline V19 & Tomateiro & Manicore & N2 \\
\hline V20 & Tomateiro & Manicore & 1 \\
\hline V21 & Tomateiro & Manicore & 1 \\
\hline V22 & Tomateiro & Carauri & 1 \\
\hline V 23 & Tomateiro & Itacoatiara & 1 \\
\hline $\mathrm{V} 24^{1}$ & Tomateiro & Tabatinga & 1 \\
\hline $\mathrm{V} 25^{1}$ & Pimentão & Benjamim Constant & 3 \\
\hline V $26^{1}$ & Pimentão & Coari & 3 \\
\hline $\mathrm{V} 27^{1}$ & Pimentao & Boaca do Acre & 3 \\
\hline V28 & Pimentão & Parintins & 1 \\
\hline$V 29^{1}$ & Pimentão & Rio Preto da Eva & 3 \\
\hline V30 & Pimentão & Manacapuru & 3 \\
\hline V31 & Pimentão & São Gabriel da Cachoeira & 1 \\
\hline V $32^{1}$ & Pimentão & Manaus & 1 \\
\hline V33 & Pimentão & Manaus & 1 \\
\hline$V 34^{1}$ & Pimenta-de-cheiro & Benjamim Constant & 3 \\
\hline V35 & Pimenta-de-cheiro & Coari & 3 \\
\hline V $36^{1}$ & Pimenta-de-cheiro & Tefé & 3 \\
\hline V37 & Pimentão & Manaus & 1 \\
\hline V38 & Berinjela & Benjamim Constant & 1 \\
\hline V39 & Berinjela & Parintins & 1 \\
\hline V41 & Berinjela & São Gabriel da Cachoeira & 1 \\
\hline $\mathrm{V} 42^{1}$ & Jiló & São Gabriel da Cachoeira & 1 \\
\hline V43 & Jiló & São Gabriel da Cachoeira & N2 \\
\hline V44 & Pepino & São Gabriel da Cachoeira & 1 \\
\hline $\mathrm{V} 45^{1}$ & Pepino & São Gabriel da Cachoeira & 1 \\
\hline V46 & Melanthera discoidea & Coari & 1 \\
\hline $\mathrm{V} 47^{1}$ & M. discoidea & Humaitá & 1 \\
\hline V48 & M. discoidea & Humaitá & 1 \\
\hline V49 & M. discoidea & Manaus & 1 \\
\hline V50 & M. discoidea & Manaus & 3 \\
\hline V51 & Erva moura & Manacapuru & 3 \\
\hline V52 & Asteraceae (não identificada) & Humaitá & 1 \\
\hline V53 & M. discoidea & Itacoatiara & 1 \\
\hline V54 & Tomateiro & Manaus & 3 \\
\hline V55 & Tomateiro & Manaus & 1 \\
\hline $\mathrm{M}^{1}{ }^{1}$ & Moringa & Manaus & 1 \\
\hline M4 & Moringa & Manaus & 1 \\
\hline $\mathrm{B} 52^{1}$ & Bananeira & Tabatinga & 1 \\
\hline $\mathrm{K} 13^{1,2}$ & Tomateiro (cv. Yoshimatsu) & Manaus & 3 \\
\hline $\mathrm{K} 73^{1,2}$ & Tomateiro (cv. Yoshimatsu) & Manaus & 1 \\
\hline $\mathrm{K} 96^{, 1,2}$ & Tomateiro (cv. Sta. Cruz Kada) & Manaus & 1 \\
\hline $\mathrm{K} 97^{1,1,2}$ & Tomateiro (cv. Sta. Cruz Kada) & Manaus & 3 \\
\hline
\end{tabular}

${ }^{1}$ Estirpes utilizadas como produtoras de bacteriocinas.

${ }^{2}$ Estirpes não avaliadas quanto a sensibilidade a bacteiocinas; obtidas em experimento em Manaus

O Moko da bananeira mostrou-se endêmico em muitos dos municípios visitados. A incidência da doença, no entanto, foi menos severa nas várzeas dos rios Madeira e Negro do que nas dos rios Solimões e Amazonas.

\section{Caracterização bioquímica dos isolados e determinação de raça}

Com os isolados de $R$. solanacearum, coletados no Estado, foi organizada uma coleção de 320 acessos. Todos os isolados não obtidos de bananeira e de helicônia foram da raça 1. Estes provocaram murcha nas hospedeiras da família Solanaceae e não foram patogênicos à bananeira. As estirpes obtidas de bananeira e de helicônia (foram classificadas como da raça 2 e foram patogênicas para bananeira, algumas delas foram também patogênicas a solanáceas. Entre os isolados foram identificadas três biovares. A biovar 1 foi a mais freqüentemente encontrada ( $73 \%$ dos isolados) e obtida de todas as hospedeiras citadas. As estirpes da biovar 1, obtidas 
de bananeira e de helicônia, se distinguiram das demais, por não acidificarem o meio contendo trealose, como única fonte de carbono. As estirpes da biovar 3 (19,2\% do total) foram obtidas de plantas de pimentão, pimenta-de-cheiro, pimenta malagueta, tomate, S. nigrum e M. discoidea. A biovar 2 tropical (7,8\% do total), também denominada de N2 (Gillings \& Fahy, 1994), foi isolada de tomateiros nos municípios de Benjamim Constant, Manicoré e Manaus, e de jiló no município de São Gabriel da Cachoeira. Na inoculação de plantas de pepino com 28 estirpes provenientes de hospedeiras diversas, apenas duas estirpes (uma da biovar 1, proveniente de bananeira, e uma da biovar 3, proveniente de pimentão) foram patogênicas à cultura.

\section{Sensibilidade a bacteriocinas}

Das 26 soluções de bacteriocinas testadas, 23 tiveram reação diferencial com as 56 estirpes selecionadas. O dendrograma das distâncias de ligação entre as estirpes (Figura 2), considerando a distância de ligação 3, permitiu que as estirpes pudessem ser divididas em seis grupos. A participação das estirpes nos grupos independeu da hospedeira e do local de origem. Estirpes provenientes da mesma hospedeira e localização, como M1 e M4, foram classificadas em grupos diferentes enquanto que as estirpes da biovar 3, de várias hospedeiras e origens geográficas distintas, foram classificados no mesmo grupo. Entre as estirpes das biovares 1 e N2, uma grande diversidade na reação a bacteriocinas foi observada. No caso da biovar 1, em 35 estirpes encontraram-se 24 fenótipos que foram divididos em cinco grupos, e nas cinco estirpes da biovar N2, cinco fenótipos foram encontrados, divididos em quatro grupos. No caso de estirpes da biovar 3, no entanto, a diversidade foi reduzida e observaram-se apenas quatro fenótipos, em 16 estirpes. Dessas 16 estirpes, 14 possuíam fenótipos idênticos ou muito semelhantes.

\section{DISCUSSÃO}

A murcha bacteriana é uma doença endêmica em hortaliças no estado do Amazonas. A ausência de isolados de $R$. solanacearum em solanáceas em sete municípios foi, provavelmente, decorrente da não localização ou da não procura de plantios dessas espécies naqueles municípios. Em áreas de várzea, muitos dos plantios de tomateiros visitados estavam abandonados em decorrência da incidência da murcha bacteriana, o que indica a importância da doença nessas áreas de produção. Por outro lado, o cultivo do pepino no Estado não pareceu ameaçado pela ocorrência de murcha bacteriana, como sugerido por Parente et al. (1990). Encontraram-se plantas de pepino com sintomas de murcha apenas no município de São Gabriel da Cachoeira e, nesse caso, as plantas estavam consorciadas com solanáceas altamente infetadas por $R$. solanacearum. A baixa freqüência de estirpes de $R$. solanacearum patogênicas a plantas de pepino, apenas duas entre as 28 testadas, poderia explicar o caráter ocasional da doença no Estado. Nesse levantamento foi constatada, pela primeira vez no continente Americano, a ocorrência da murcha bacteriana em moringa (Coelho Netto et al., 2000), uma espécie recentemente introduzida na região. Também a primeira constatação da infecção da planta daninha $M$. discoidea, por $R$. solanacearum, foi feita nesse levantamento (Coelho Netto et al., 2001). Essa e outras espécies de plantas daninhas encontradas infetadas por $R$. solanacearum, como $S$. nigrum, podem servir de reservatório do patógeno, contribuindo para a manutenção da população da bactéria no solo.

A morfologia das colônias das estirpes obtidas de bananeiras e a virulência dessas estirpes a solanáceas foi semelhante a das estirpes peruanas denominadas tipo A por French \& Sequeira (1970). Essa constatação, juntamente com a observação do endemismo da doença nos municípios banhados pelos rios Solimões e Amazonas e a menor incidência do Moko nas várzeas dos rios Madeira e Negro, fortalece a hipótese de French \& Sequeira (1970) sobre a dispersão do patógeno através dos rios Maranõn e Ucayali no Peru. A partir destes rios, a disseminação da bactéria provavelmente continuou através dos Rios Solimões e Amazonas, no Brasil.

A contaminação das inflorescências de bananeiras por $R$. solanacearum foi constatada com freqüência; todavia, a transmissão da bactéria via insetos, sugerida por Buddenhagen \& Elsasser (1962), ainda precisa ser demonstrada.

Apesar da biovar 1, na maioria das hospedeiras, ser a mais freqüente, com a raça 2 infetando bananeira e a raça 1 infetando os demais hospedeiras. Em estirpes provenientes de pimentão e de pimenta-de-cheiro observou-se uma predominância de estirpes da biovar 3. A biovar N2, isolada principalmente de tomateiros e raramente encontrada no Estado, é metabolicamente mais versátil que a biovar 2 (raça 3), freqüentemente obtida de plantas de batata na região Andina (Gillings \& Fahy, 1993). Em três localidades, das quatro onde a biovar N2 foi isolada, tratava-se do primeiro plantio de solanáceas na área, após o desmatamento, sugerindo a presença de uma hospedeira nativa e ainda não identificada de $R$. solanacearum, na floresta. Apesar de poder apresentar elevada virulência a tomateiros, a biovar N2 apresenta menor sobrevivência no solo do que as biovares 1 ou 3 (Pereira et al., 2001). Elphinstone (1992), avaliando estirpes de $R$. solanacearum provenientes de diversos países do mundo, encontrou uma estirpe da biovar N2 agressiva a uma variedade de tomateiro resistente às biovares 1 e 3 . Assim, apesar da biovar N2 aparentemente não representar um perigo para o cultivo do tomateiro no Estado, faz-se necessário um monitoramento da sua ocorrência.

A produção de bacteriocinas por estirpes de $R$. solanacearum tem se mostrado um fenômeno bastante freqüente. Frey et al. (1996), utilizando análise genética (repPCR e RC-PFGE) e de sensibilidade a bacteriocinas, observaram uma alta correlação entre as estirpes componentes dos grupos formados pela análise através das duas técnicas. No presente estudo, das 16 estirpes da biovar 3 avaliadas, 14 enquadraramse no grupo VI, indicando uma menor variabilidade genética das estirpes dessa biovar. As estirpes das biovares 1 e N2 foram bastante variáveis e não se percebeu uma relação entre a sensibilidade a bacteriocinas e a hospedeira ou a origem geográfica da estirpe. Embora o tamanho da amostra nesse 


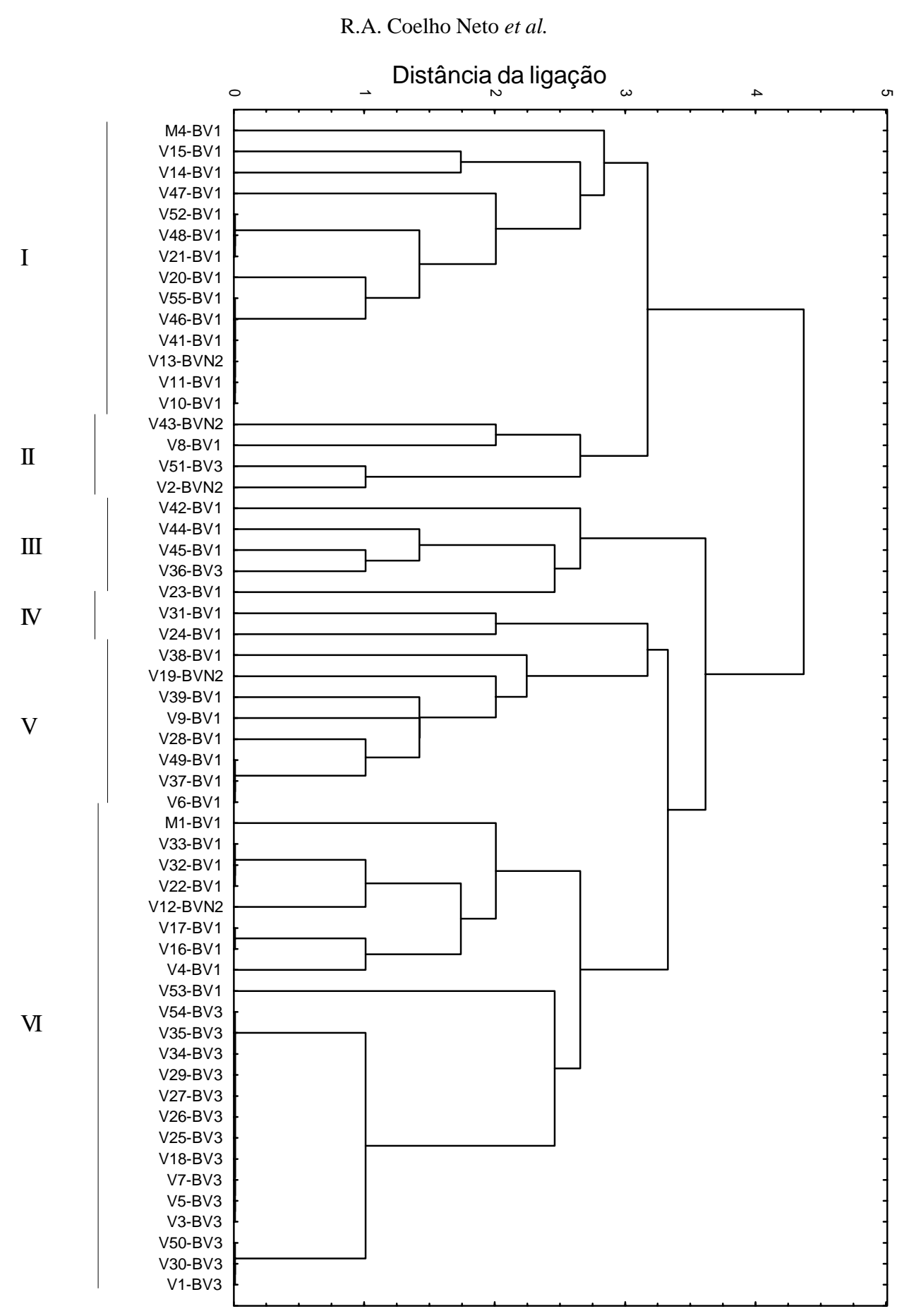

FIG. 2 - Denc

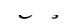
diferentes hospedeiras e municípios do estado do Amazonas, com relação a sensibilidade a bacteriocinas produzidas por 23 estirpes.

estudo não seja adequada para se obter conclusões definitivas sobre a estrutura da população, essas informações serão úteis em futuros estudos genéticos da variabilidade da população de $R$. solanacearum no estado do Amazonas.

\section{REFERÊNCIAS BIBLIOGRÁFICAS}

BUDDENHAGEN, I.W. \& ELSASSER, T.A. An insect-spread bacterial wilt epiphytotic of Bluggoe banana. Nature 194:164-165. 1962.

BUDDENHAGEN, I.W., SEQUEIRA, L. \& KELMAN, A. Designation of races in Pseudomonas solanacearum. Phytopathology 52:726. 1962.

COELHO NETTO, R.A., MARENCO, K.R., PEREIRA, B.G., NODA, H. \& BOHER, B. Ocorrência de murcha bacteriana em moringa causada por Ralstonia solanacearum. Fitopatologia Brasileira 25:670. 
2000. (Resumo)

COELHO NETTO, R.A., NODA, H. \& BOHER, B. Melanthera discoidea Brake: um novo hospedeiro de Ralstonia solanacearum. Fitopatologia Brasileira 26:781. 2001. (Resumo)

CUPPELS, D.A., HANSON, R.S. \& KELMAN, A. Isolation and characterization of bacteriocin produced by Pseudomonas solanacearum. Journal of General Microbiology 109:295-303. 1978.

ELPHINSTONE, J.G. Virulence of isolates of Pseudomonas solanacearum from worldwide sources on resistant and susceptible tomato cultivars. In: Lemattre, M., Freigoun, S., Rudolph, K. \& Swings, J.G. (Eds.) Plant Pathogenic Bacteria, Versailles, INRA. 1992. pp. 599-604.

FAHY, P.C. \& PERSLEY, G.J. Plant bacterial diseases. A diagnostic guide. Sydney. Academic Press. 1983.

FRENCH, E.R. \& SEQUEIRA, L. Strains of Pseudomonas solancearum from Central and South America: a comparative study. Phytopathology, 60:506-512. 1970.

FREY, P., SMITH, J.J., ALBAR, L., PRIOR, P., SADDLER, G.S., TRIGALET-DEMERY, D. \& TRIGALET, A. Bacteriocin typing of Burkholderia (Pseudomonas) solanacearum race 1 of the French West Indies and correlation with genomic variation of the pathogen. Applied and Environmental Microbiology 62:473-479. 1996.

GILLINGS, M.R. \& FAHY, P. Genetic diversity of Pseudomonas solanacearum biovars 2 and $\mathrm{N} 2$ assessed using restriction endonuclease analysis of total genomic DNA. Plant Pathology 42:744-753. 1993.

GILLINGS, M.R. \& FAHY, P. Genomic fingerprinting: towards a unified view of the Pseudomonas solanacearum species complex. In: Hayward, A.C. \& Hartman, G.L. (Eds.). Bacterial wilt: The disease and its causative agent, Pseudomonas solanacearum, Wallingford. CAB. 1994. pp.95-112.

HAYWARD, A.C. Systematics and phylogeny of Pseudomonas solanacearum and related bacteria. In: Hayward, A.C. \& Hartman, G.L. (Eds.). Bacterial wilt: The disease and its causative agent, Pseudomonas solanacearum. Wallingford. CAB. 1994. pp.123-135.

HAYWARD, A.C. Biology and epidemiology of bacterial wilt caused by Pseudomonas solanacearum. Annual Review of Phytopathology 29:65-87. 1991.

HAYWARD, A.C. Technique for the study of Pseudomonas solanacearum. In: Sequeira, L. \& Kelman A. (Eds.). Proceedings of the First International Planning Conference and Workshop on the Ecology and Control of Bacterial Wilt Caused by Pseudomonas solanacearum. Raleigh. North Carolina State University. 1976. pp.137-142.

HE, L., SEQUEIRA, L. \& KELMAN, A. Characteristics of strains of Pseudomonas solanacearum from China. Plant Disease. 67:13571361. 1983.

KELMAN, A. The relationship of pathogenicity in Pseudomonas solanacearum to colony appearance on a tetrazolium medium. Phytopathology 44:693-695. 1954.

LOPES, C.A. \& QUEZADO-SOARES, A.M. Doenças bacterianas das hortaliças - diagnose e controle. Brasília: Embrapa - CNPH. 1997.

MARTINS, O.M., TAKATSU, A. \& REIFSCHNEIDER, J.B. Virulência de biovares I e III de Pseudomonas solanacearum ao tomateiro. Fitopatologia Brasileira 13:249-252. 1988.

MARTINS, O.M. \& TAKATSU, A. Doenças de hortaliças no Amapá. Fitopatoloiga Brasileira 15:357-359. 1990.

MELO, M.S., FURUYA, N., IIYAMA, K., KHAN, A.A. \& MATSUYAMA, N. Geographical distribution of biovars of Ralstonia solanacearum in Brazil. Journal of the Faculty of Agriculture Kyushu University 44:9-15. 1999.

PARENTE, P.M.G., TAKATSU, A. \& LOPES, C. Virulência de isolados de Pseudomonas solanacearum obtidos de pepino a algumas solanáceas e sensibilidade do pepino ao patógeno isolado de diferentes hospedeiros. Fitopatologia Brasileira 15:31-33. 1990.

PEREIRA, B.G., COELHO NETTO, R.A. \& BOHER, B. Avaliação de espécies na supressão de Ralstonia solanacearum. Fitopatologia Brasileira 26:545. 2001.

REIFSCHNEIDER, F.J.B. \& TAKATSU, A. Pseudomonas solanacearum. Aspectos macro-epidemiológicos. Fitopatologia Brasileira 10:213. 1985 (Resumo) 